\section{Elucidation of disease mechanisms underlying rheumatic immune-related adverse events may lead to novel therapeutic strategies for autoimmune diseases}

We read with great interest the article 'EULAR points to consider for the diagnosis and management of rheumatic immune-related adverse events due to cancer immunotherapy with checkpoint inhibitors' by Kostine et al. ${ }^{1}$ In this article, the authors performed a systematic literature review and generated the first set of recommendations for the diagnosis and management of rheumatic immune-related adverse events (irAEs) induced by checkpoint inhibitors. ${ }^{1}$ As the authors noted, the paucity of literature on this issue has led to empirical treatment that is not based on evidence. Their points to consider provide a rationale for the management of rheumatic irAEs, as well as help rheumatologists engage with oncologists, thereby enabling patients with cancer to maintain a better quality of life. We have reported on the role of the programmed cell death protein-1 (PD-1) checkpoint in various vascular pathologies ${ }^{2-4}$ and thus wanted to comment on this article, since vasculitis can occur as a type of rheumatic irAEs. ${ }^{5} 6$

First, the article stated that irAEs can affect any organ and cause a wide variety of autoimmune disease-like pathologies, with an estimated prevalence of 1.5\%-22\%; however, the risk factors for rheumatic irAEs remain unclear. Risk factors for exacerbation in patients with pre-existing rheumatic disease also remain unidentified. Recent studies have reported that variation in human leucocyte antigen is associated with the development of irAEs, such as colitis and adrenal insufficiency. ${ }^{78}$ Further studies are needed to identify risk factors for rheumatic irAEs. ${ }^{9}$

Second, three treatment escalations for rheumatic irAEs were defined in the article: local/systemic glucocorticoids, conventional synthetic disease-modifying antirheumatic drugs (DMARDs) and biological DMARDs. ${ }^{1}$ However, there are still many unanswered questions. For example, how do we reduce or discontinue these immunomodulators or when do we resume cancer immunotherapy? It is also of importance to monitor whether these immunosuppressive agents interfere with checkpoint inhibitors.

Third, and most importantly, as the authors highlighted in their research agenda, a better understanding of the pathophysiology of rheumatic irAEs is crucial. Early reports of fulminant myocarditis due to checkpoint inhibitors demonstrated that activated $\mathrm{T}$ cells were the main players in irAE pathology. ${ }^{10}{ }^{11}$ Using an experimental mouse model of large vessel vasculitis, we have previously reported that blockade of PD-1 signalling not only exacerbated vascular inflammation through the infiltration of activated $T$ cells but also caused intimal thickening and adventitial neovascularisation, indicating that activated $\mathrm{T}$ cells play a central role in vascular remodelling. ${ }^{23}$ What we want to emphasise here is that the disease mechanisms underlying rheumatic irAEs should be investigated, which may lead to novel therapeutic strategies for autoimmune diseases.

Despite the many unsolved problems, this article raised awareness of rheumatic irAEs among rheumatologists and created a blueprint for therapeutic strategies. Further studies are needed to better define basic and clinical aspects of rheumatic irAEs.

\section{Ryu Watanabe ${ }^{1},{ }^{1,2}$ Motomu Hashimoto ${ }^{1,2}$}

${ }^{1}$ Department of Rheumatology and Clinical Immunology, Kyoto University Graduate School of Medicine, Kyoto, Japan

${ }^{2}$ Department of Advanced Medicine for Rheumatic Disease, Kyoto University Graduate School of Medicine, Kyoto, Japan

Correspondence to Dr Ryu Watanabe, Department of Rheumatology, Osaki Citizen Hospital, Osaki 989-6136, Japan; ryuwatanabe@kuhp.kyoto-u.ac.jp

Contributors RW wrote the manuscript and MH finalised it.

Funding The authors have not declared a specific grant for this research from any funding agency in the public, commercial or not-for-profit sectors.

Competing interests $\mathrm{MH}$ received research grants and/or speaker fees from Brystol-Meyers, Eisai, Eli Lilly and Tanabe-Mitsubishi. Department of Advanced Medicine for Rheumatic Diseases is supported by five pharmaceutical companies (Mitsubishi Tanabe Pharma Co., Chugai Pharmaceutical Co. Ltd, UCB Japan Co. Ltd, AYUMI Pharmaceutical Co. and Asahi Kasei Pharma Co.). These companies did not participate in the writing of the manuscript or decision to submit the manuscript for the publication.

Patient and public involvement Patients and/or the public were not involved in the design, conduct, reporting or dissemination plans of this research.

Patient consent for publication Not required.

Provenance and peer review Not commissioned; internally peer reviewed.

(C) Author(s) (or their employer(s)) 2020. No commercial re-use. See rights and permissions. Published by BMJ.

$$
\text { Check for updates }
$$

To cite Watanabe R, Hashimoto M. Ann Rheum Dis Epub ahead of print: [please include Day Month Year]. doi:10.1136/annrheumdis-2020-217995

Received 15 May 2020

Accepted 15 May 2020

Ann Rheum Dis 2020;0:1. doi:10.1136/annrheumdis-2020-217995

ORCID iD

Ryu Watanabe http://orcid.org/0000-0002-1089-5296

\section{REFERENCES}

1 Kostine M, Finckh A, Bingham CO, et al. EULAR points to consider for the diagnosis and management of rheumatic immune-related adverse events due to cancer immunotherapy with checkpoint inhibitors. Ann Rheum Dis 2020. doi:10.1136/ annrheumdis-2020-217139

2 Zhang $\mathrm{H}$, Watanabe R, Berry GJ, et al. Immunoinhibitory checkpoint deficiency in medium and large vessel vasculitis. Proc Natl Acad Sci U S A 2017;114:E970-9.

3 Watanabe R, Zhang H, Berry G, et al. Immune checkpoint dysfunction in large and medium vessel vasculitis. Am J Physiol Heart Circ Physiol 2017;312:H1052-9.

4 Watanabe R, Shirai T, Namkoong H, et al. Pyruvate controls the checkpoint inhibitor PD-L1 and suppresses T cell immunity. J Clin Invest 2017;127:2725-38.

5 Salem J-E, Manouchehri A, Moey M, et al. Cardiovascular toxicities associated with immune checkpoint inhibitors: an observational, retrospective, pharmacovigilance study. Lancet Oncol 2018;19:1579-89.

6 Goldstein BL, Gedmintas L, Todd DJ. Drug-Associated polymyalgia rheumatica/giant cell arteritis occurring in two patients after treatment with ipilimumab, an antagonist of CTLA-4. Arthritis Rheumatol 2014;66:768-9.

7 Hasan Ali O, Berner F, Bomze D, et al. Human leukocyte antigen variation is associated with adverse events of checkpoint inhibitors. Eur J Cancer 2019;107:8-14.

8 Yano S, Ashida K, Sakamoto R, et al. Human leucocyte antigen DR15, a possible predictive marker for immune checkpoint inhibitor-induced secondary adrenal insufficiency. Eur J Cancer 2020;130:198-203.

9 Ramos-Casals M, Brahmer JR, Callahan MK, et al. Immune-Related adverse events of checkpoint inhibitors. Nat Rev Dis Primers 2020;6:38.

10 Johnson DB, Balko JM, Compton ML, et al. Fulminant myocarditis with combination immune checkpoint blockade. N Engl J Med 2016;375:1749-55.

11 Postow MA, Sidlow R, Hellmann MD. Immune-Related adverse events associated with immune checkpoint blockade. N Engl J Med 2018;378:158-68. 